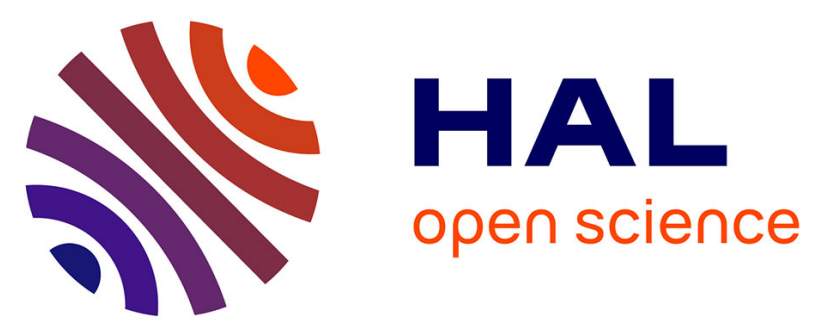

\title{
China's emission control strategies have suppressed unfavorable influences of climate on wintertime PM2.5 concentrations in Beijing since 2002
}

Meng Gao, Zirui Liu, Bo Zheng, Dongsheng Ji, Peter Sherman, Shaojie Song, Jinyuan Xin, Cheng Liu, Yuesi Wang, Qiang Zhang, et al.

\section{To cite this version:}

Meng Gao, Zirui Liu, Bo Zheng, Dongsheng Ji, Peter Sherman, et al.. China's emission control strategies have suppressed unfavorable influences of climate on wintertime PM2.5 concentrations in Beijing since 2002. Atmospheric Chemistry and Physics, 2020, 20 (3), pp.1497-1505. 10.5194/acp20-1497-2020 . hal-03228156

\section{HAL Id: hal-03228156 \\ https://hal.science/hal-03228156}

Submitted on 7 Jun 2021

HAL is a multi-disciplinary open access archive for the deposit and dissemination of scientific research documents, whether they are published or not. The documents may come from teaching and research institutions in France or abroad, or from public or private research centers.
L'archive ouverte pluridisciplinaire $\mathbf{H A L}$, est destinée au dépôt et à la diffusion de documents scientifiques de niveau recherche, publiés ou non, émanant des établissements d'enseignement et de recherche français ou étrangers, des laboratoires publics ou privés. 


\title{
China's emission control strategies have suppressed unfavorable influences of climate on wintertime $\mathbf{P M}_{2.5}$ concentrations in Beijing since 2002
}

\author{
Meng Gao ${ }^{1,2,3}$, Zirui Liu ${ }^{4}$, Bo Zheng ${ }^{5,6}$, Dongsheng $\mathbf{J i}^{4}$, Peter Sherman ${ }^{7}$, Shaojie Song ${ }^{3}$, Jinyuan Xin ${ }^{4}$, Cheng Liu ${ }^{8}$, \\ Yuesi Wang ${ }^{4}$, Qiang Zhang ${ }^{5}$, Jia Xing ${ }^{9}$, Jingkun Jiang ${ }^{9}$, Zifa Wang ${ }^{4}$, Gregory R. Carmichael ${ }^{10}$, and \\ Michael B. McElroy ${ }^{3,7}$ \\ ${ }^{1}$ Department of Geography, Hong Kong Baptist University, Hong Kong SAR, China \\ ${ }^{2}$ State Key Laboratory of Environmental and Biological Analysis, Hong Kong Baptist University, Hong Kong SAR, China \\ ${ }^{3}$ John A. Paulson School of Engineering and Applied Sciences, Harvard University, Cambridge, MA 02138, USA \\ ${ }^{4}$ State Key Laboratory of Atmospheric Boundary Layer Physics and Atmospheric Chemistry, Institute of Atmospheric \\ Physics, Chinese Academy of Sciences, Beijing, 100029, China \\ ${ }^{5}$ Ministry of Education Key Laboratory for Earth System Modeling, Department of Earth System Science, \\ Tsinghua University, Beijing, 100084, China \\ ${ }^{6}$ Laboratoire des Sciences du Climat et de l'Environnement, CEA-CNRS-UVSQ, UMR 8212, 91198 Gif-sur-Yvette, France \\ ${ }^{7}$ Department of Earth and Planetary Sciences, Harvard University, Cambridge, MA 02138, USA \\ ${ }^{8}$ University of Science and Technology of China, Hefei, Anhui, 230026, China \\ ${ }^{9}$ State Key Joint Laboratory of Environmental Simulation and Pollution Control, School of Environment, \\ Tsinghua University, Beijing, 100084, China \\ ${ }^{10}$ Department of Chemical and Biochemical Engineering, The University of Iowa, Iowa City, IA 52242, USA
}

Correspondence: Meng Gao (mmgao2@hkbu.edu.hk), Zifa Wang (zifawang@mail.iap.ac.cn)

and Michael B. McElroy (mbm@seas.harvard.edu)

Received: 3 April 2019 - Discussion started: 23 May 2019

Revised: 29 October 2019 - Accepted: 24 December 2019 - Published: 7 February 2020

\begin{abstract}
Severe wintertime $\mathrm{PM}_{2.5}$ pollution in Beijing has been receiving increasing worldwide attention, yet the decadal variations remain relatively unexplored. Combining field measurements and model simulations, we quantified the relative influences of anthropogenic emissions and meteorological conditions on $\mathrm{PM}_{2.5}$ concentrations in Beijing over the winters of 2002-2016. Between the winters of 2011 and 2016, stringent emission control measures resulted in a $21 \%$ decrease in mean mass concentrations of $\mathrm{PM}_{2.5}$ in Beijing, with 7 fewer haze days per winter on average. Given the overestimation of $\mathrm{PM}_{2.5}$ by the model, the effectiveness of stringent emission control measures might have been slightly overstated. With fixed emissions, meteorological conditions over the study period would have led to an increase in haze in Beijing, but the strict emission control measures have suppressed the unfavorable influences of the recent climate. The
\end{abstract}

unfavorable meteorological conditions are attributed to the weakening of the East Asia winter monsoon associated particularly with an increase in pressure associated with the Aleutian Low.

\section{Introduction}

In recent years, persistent and severe haze episodes with high $\mathrm{PM}_{2.5}$ concentrations occur frequently in China, attracting worldwide attention (Cheng et al., 2016; Gao et al., 2016a). High aerosol concentrations during haze have been reported to cause traffic jams and flight cancelations (Wu et al., 2005) and have been linked to health damage (Dockery et al., 1993), climate change (Ramanathan and Carmichael, 2008), and ecosystem degradation (Chameides et al., 1999). 
The annual mean $\mathrm{PM}_{2.5}$ concentrations in Beijing exceeded $90 \mu \mathrm{g} \mathrm{m}^{-3}$ in 2013, nearly twice China's National Ambient Air Quality Standard (NAAQS) of $35 \mu \mathrm{g} \mathrm{m}^{-3}$ (Ministry of Environmental Protection (MEP) 2012). January 2013 was reported as the haziest month over the past 60 years in Beijing, with maximum hourly and daily mean $\mathrm{PM}_{2.5}$ concentrations exceeding 1000 and $500 \mu \mathrm{g} \mathrm{m}^{-3}$, respectively (Wang et al., 2014).

Since then, the State Council of China has issued the Air Pollution Prevention and Control Action Plan (APPCAP), which describes explicitly the pollution control measures, and proposed specific goals for concentrations by 2017 (China State Council, 2013). This action has been considered the most stringent air pollution control policy in Chinese history. The Beijing-Tianjin-Hebei, Yangtze River Delta, and Pearl River Delta regions were required to reduce annual mean $\mathrm{PM}_{2.5}$ concentrations by $15 \%-25 \%$ compared with the concentrations in 2013, and the annual mean concentrations of $\mathrm{PM}_{2.5}$ in Beijing should not exceed $60 \mu \mathrm{g} \mathrm{m}^{-3}$ (Cheng et al., 2019; China State Council, 2013). Specific control measures included eliminating small coal-fired boilers, phasing out small high-emitting factories, installing control facilities for emissions of VOCs (volatile organic compounds), and replacing residential coal burning with electricity and natural gas among others (Zheng et al., 2018). With these rigorous control measures, China has made impressive progress, with annual mean $\mathrm{PM}_{2.5}$ concentrations reduced in major metropolitan regions by $28 \%-40 \%$ between 2013 and 2017 (Zheng et al., 2018).

A number of studies have used visibility as a surrogate to indicate trends of haze pollution in China over the past several decades (Che et al., 2009; Chen and Wang, 2015; Ding and Liu, 2014; Wang and Chen, 2016). Chen and Wang (2015) reported that haze days increased rapidly in the 1970 s and remained relatively stable up to the present. However, Che et al. (2009) illustrated that there was a decreasing haze trend in winter for many cities over the interval 19812005. Wang et al. (2019) argued that visibility is impacted significantly by meteorological factors, especially relative humidity, and thus visibility does not accordingly reflect the real changes in air pollution. The influences of anthropogenic emissions and meteorological conditions on air quality over shorter periods have been investigated extensively (Gao et al., 2017a, 2011; Liu et al., 2017; Wang et al., 2016; Xing et al., 2011). Due to the lack of long-term measurements of $\mathrm{PM}_{2.5}$ in China, limited studies have been conducted exploring the roles of anthropogenic emissions and meteorological conditions for the long-term variations of $\mathrm{PM}_{2.5}$ in China. Yang et al. (2016) used the GEOS-Chem model to simulate $\mathrm{PM}_{2.5}$ in China between 1985 and 2005 and concluded that the increase in winter $\mathrm{PM}_{2.5}$ was dominated over this period by the increase in anthropogenic emissions. They found that weakening of winds was the dominant meteorological factor. The variability of winds in North China has also been linked to air quality over the Yangtze River Delta, which is a

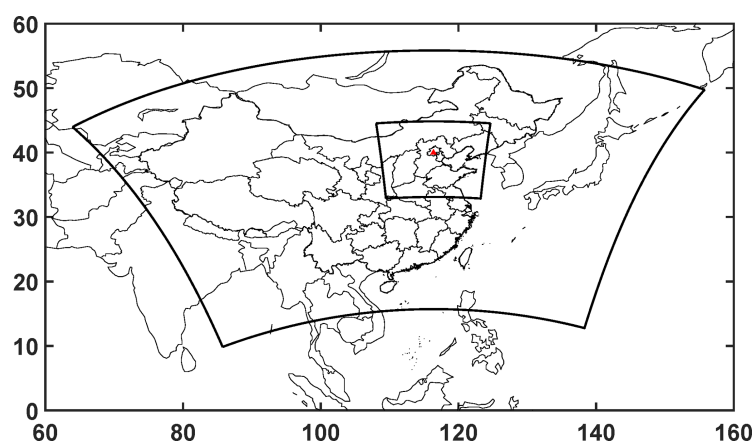

Figure 1. WRF-Chem modeling domain settings and locations of observations.

downwind region of North China (Kang et al., 2019). While Yang et al. (2016) have explored the relative roles of emissions and meteorology, no model validation of $\mathrm{PM}_{2.5}$ was provided, and the recent decades were not covered in the study period. Long-term measurements of $\mathrm{PM}_{2.5}$ in Beijing reveal a slight decreasing trend of annual mean concentration over 2004-2012 (Liu et al., 2015). With the increase in availability of recent measurements, a closer reading of longterm variations is needed to better define the relative roles of anthropogenic emissions and meteorology.

In this study, we present a comprehensive analysis of the decadal trend of wintertime $\mathrm{PM}_{2.5}$ in Beijing based on regional meteorology-chemistry modeling, a new decadal emission inventory, and long-term observations of $\mathrm{PM}_{2.5}$, including their composition. We address the following topics: (1) the influences of decadal changes in anthropogenic emissions and meteorology on the variations of winter $\mathrm{PM}_{2.5}$ in Beijing and (2) the key driving factors for the decadal variation of meteorology. The descriptions of model, emissions, and numerical experiments are presented in Sect. 2. The two questions highlighted above are addressed in detail in Sect. 3; Sect. 4 provides an overall summary of the study.

\section{Model description and configurations}

\subsection{Meteorology-chemistry modeling}

We used the WRF-Chem (Weather Research and Forecasting model coupled with chemistry) model version 3.6.1 to simulate meteorology and emissions, transport, mixing, and the chemical transformation of trace gases and aerosols. Two nested domains were applied with the outer domain covering East Asia and part of Southeast Asia and with the inner domain focusing on North China (Fig. 1). Horizontal resolutions of 81 and $27 \mathrm{~km}$ were configured for these two domains, respectively, and the model accounted for 27 vertical layers extending from the surface to $50 \mathrm{hPa}$. The gas phase chemical mechanism CBMZ (Zaveri and Peters, 1999) coupled with the 8-bin sectional MOSAIC model with aqueous chemistry 
(Zaveri et al., 2008) was adopted. The model treats all the important aerosol species, including sulfate, nitrate, chloride, ammonium, sodium, black carbon (BC), and primary organic and inorganic material. The Fast-J radiation scheme (Wild et al., 2000) was selected to calculate photolysis rates. These configurations have been shown in previous studies (Gao et al., 2016a, b, 2017b) to be capable of reproducing winter haze episodes in North China.

\subsection{Emissions}

The monthly Multi-resolution Emission Inventory for China (MEIC, http://www.meicmodel.org/, last access: 1 May 2019) covering the years 2002-2017 (Zheng et al., 2018) was used for anthropogenic emissions. This inventory considers emissions of sulfur dioxide $\left(\mathrm{SO}_{2}\right)$, nitrogen oxides $\left(\mathrm{NO}_{x}\right)$, carbon monoxide $(\mathrm{CO})$, non-methane volatile organic compounds (NMVOC), ammonia $\left(\mathrm{NH}_{3}\right)$, black carbon (BC), organic carbon (OC), $\mathrm{PM}_{2.5}, \mathrm{PM}_{10}$, and carbon dioxide $\left(\mathrm{CO}_{2}\right)$ associated with power generation and the industrial, residential, transportation, and agricultural sectors. The trends of wintertime emissions of these species in the Beijing-Tianjin-Hebei region over the interval 2002-2016 are displayed in Fig. S1. Emissions of $\mathrm{SO}_{2}$ have decreased continuously since 2004, while $\mathrm{NO}_{x}$ emissions have declined since 2011. Emissions of all involved species have decreased rapidly since 2012. Biogenic emissions were calculated online using the MEGAN model (Guenther et al., 2006). Emissions from biomass burning were taken from the GFED v3 dataset (Randerson et al., 2015). Dust emissions and sea-salt emissions were also calculated online.

\subsection{Numerical experiments}

Meteorological initial and boundary conditions were obtained from the National Centers for Environmental Prediction (NCEP) final analysis (FNL) dataset. Chemical initial and boundary conditions were taken from the climatological data provided by the NOAA Aeronomy Lab Regional Oxidant Model (NALROM). Wintertime periods defined as the last month of the year and the following 2 months of the next year were simulated for the years 2002-2016. For example, the winter of 2002 includes December of 2002, January of 2003, and February of 2003. Nudging (assimilation) of the analyses was applied to produce realistic meteorological simulations. The simulations were conducted month by month (15 years $\times 3$ months $\mathrm{yr}^{-1}=45$ months). To overcome the impacts of initial conditions, 5 more days were simulated for each month and discarded as spin-up. Two sets of simulations were performed to elucidate the relative roles of changes in anthropogenic emissions and meteorological conditions: (1) CTL (control) simulation, simulations of winter periods from 2002 to 2016 with varying meteorological conditions and anthropogenic emissions, and (2) MET (meteorology) simulation, simulations of winter periods from 2002 to 2016 with varying meteorological conditions only, with anthropogenic emissions fixed at levels that applied in 2002. The MET simulation can be used to answer the following question: what would the climate have done to the variations of $\mathrm{PM}_{2.5}$ if emissions were not changing? The CTL simulation contains the information of changes in both meteorological conditions and emissions.

\section{Results and discussion}

\subsection{Model evaluation}

Model evaluation was conducted in terms of both $\mathrm{PM}_{2.5}$ concentrations and $\mathrm{PM}_{2.5}$ chemical compositions, using measurements from urban Beijing (location is marked with a red triangle in Fig. 1). $\mathrm{PM}_{2.5}$ was measured using the two tapered element oscillating microbalance (TEOM) systems at the Institute of Atmospheric Physics (Chinese Academy of Sciences) site. More descriptions of the observations were archived in Liu et al. (2015). Figure 2 displays the variations of simulated and observed daily mean $\mathrm{PM}_{2.5}$ concentrations over winters from 2002 to 2016. Temporal variations of simulated and observed $\mathrm{PM}_{2.5}$ concentrations are generally consistent, with correlation coefficients ranging from 0.75 to 0.83 (Fig. 2). Notably, the model overestimates $\mathrm{PM}_{2.5}$ concentrations for all periods. However, the overestimations decline gradually over time. Values of the mean bias decrease

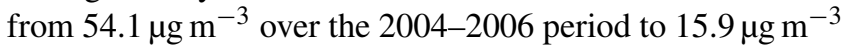
for recent winters. The broad ranges of errors in different periods reflect the changing uncertainty of emission inventories for different periods. In earlier times, documentations of emission sources were not as comprehensive as those available for recent years, leading to larger errors in early inventories.

According to results reported by Zheng et al. (2018), $\mathrm{SO}_{2}$ emissions decreased by $59 \%, \mathrm{NO}_{x}$ emissions decreased by $21 \%$, BC emissions decreased by $28 \%$, and OC emissions decreased by 32\% for China between 2013 and 2017. These remarkable changes in emissions are expected to lead to notable changes in both the abundance and composition of $\mathrm{PM}_{2.5}$. As shown in Fig. 3, sulfate and OC exhibit the largest declines and ammonium and BC show slight decreases, while nitrate concentrations remain relatively stable over 2013-2017. These measured trends are captured generally well by the model, except that sulfate is still underestimated and $\mathrm{BC}$ in Beijing is overestimated. The underestimate of sulfate by models and the overestimate of BC in Beijing have been well documented in previous studies (Cheng et al., 206; Gao et al., 2016a, 2018a; Song et al., 2018), attributed to missing reaction pathways and aging and deposition treatments in models (Song et al., 2019). Several heterogeneous reaction pathways for sulfate formation have been proposed, including the oxidation of $\mathrm{SO}_{2}$ by $\mathrm{NO}_{2}$, transitionmetal-catalyzed $\mathrm{O}_{2}$, or $\mathrm{H}_{2} \mathrm{O}_{2}$ in aerosol water and by $\mathrm{NO}_{2}$ or 

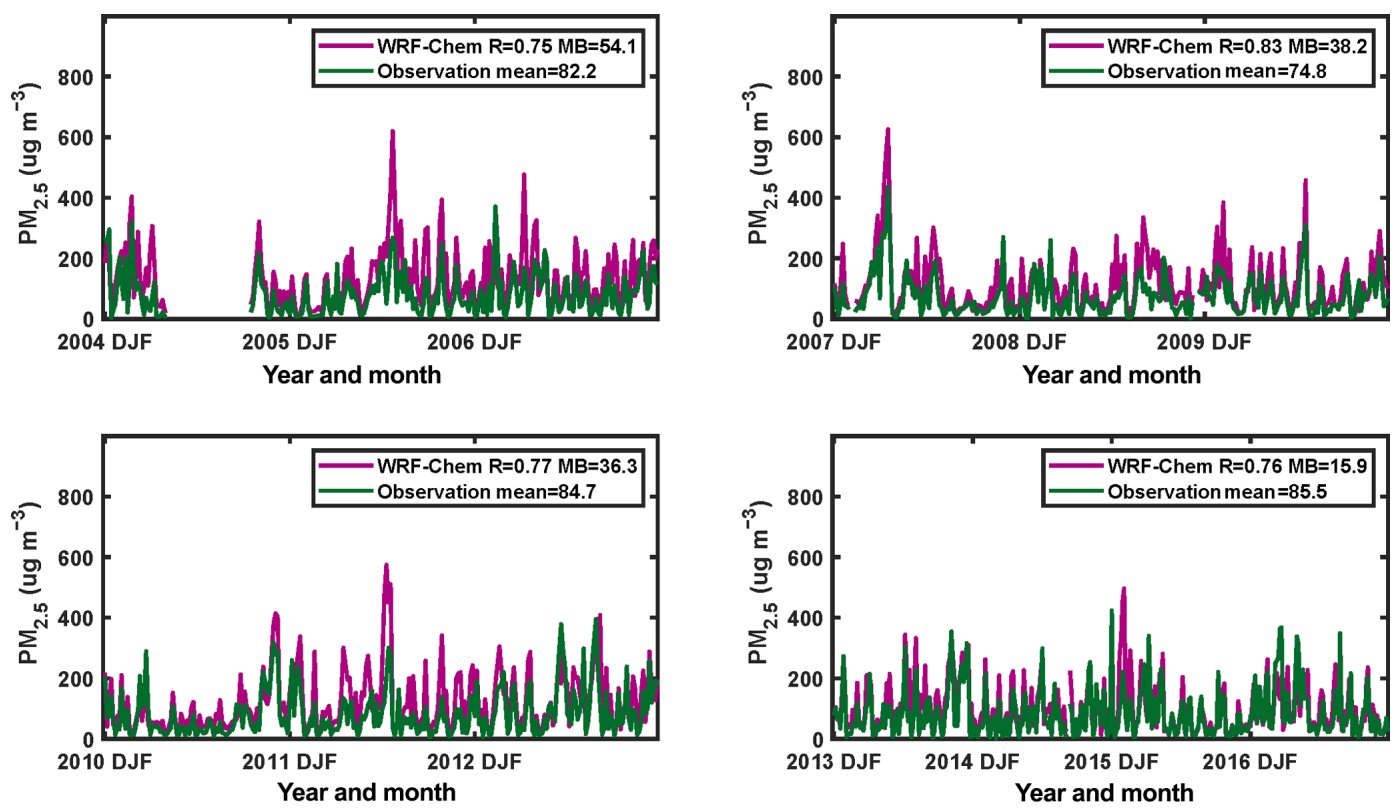

Figure 2. Simulated and observed temporal variations of daily mean $\mathrm{PM}_{2.5}$ concentrations in Beijing, with correlation coefficient and mean bias.

$\mathrm{O}_{2}$ on aerosol surfaces (Cheng et al., 2016; He et al., 2014; Hung et al., 2018; Li et al., 2018). More recently, Song et al. (2019) proposed that the heterogeneous production of hydroxymethanesulfonate (HMS) from the reaction of $\mathrm{SO}_{2}$ and formaldehyde could be an important chemical mechanism for wintertime haze in China. With the rapid declines in sulfate in Beijing, the relative importance of nitrate in $\mathrm{PM}_{2.5}$ is enhanced, a circumstance worthy of special attention for future pollution control policy.

\subsection{Influences of anthropogenic emissions and meteorological conditions on haze in Beijing}

Figure 4 illustrates the wintertime mean concentrations of $\mathrm{PM}_{2.5}$ and the numbers of haze days from the CTL and MET simulations. Haze days are defined as occasions with daily mean concentrations exceeding $150 \mu \mathrm{g} \mathrm{m}^{-3}$. With fixed anthropogenic emissions, wintertime-averaged concentrations of $\mathrm{PM}_{2.5}$ would have increased at a rate of $2.1 \mu \mathrm{g} \mathrm{m}^{-3} \mathrm{yr}^{-1}$ in Beijing (Fig. 4a). Due to the implementation of China's emission control strategies, the wintertime-averaged concentrations of $\mathrm{PM}_{2.5}$ have been declining since 2012. Over the 2002-2016 winters, mean concentrations of $\mathrm{PM}_{2.5}$ in Beijing decreased at a rate of $1.4 \mu \mathrm{g} \mathrm{m}^{-3} \mathrm{yr}^{-1}$. Compared to concentrations in the MET simulation, the mean mass concentrations of $\mathrm{PM}_{2.5}$ decreased by $21 \%$ in Beijing over the winters of 2011-2016.

The effectiveness of China's emission control strategies has been highlighted also in the decline in the number of haze days in Beijing. In the MET simulation, the total number of haze days over the 2011-2016 winters amounted to
$157 \mathrm{~d}$, reduced by $44 \mathrm{~d}$ as a result of the emission controls implemented over this period (Fig. 4b). On average, China's emission control strategies resulted in 7 fewer haze days per winter over 2011-2016. Over the entire study period 20022016, China's emission control strategies altered the direction of changes in wintertime haze days, with rates changing from 0.8 to $0.3 \mathrm{dyr}^{-1}$. The differences in both mean concentrations of $\mathrm{PM}_{2.5}$ and numbers of haze days from the two sets of simulations underscore the impressive success of China's emission control strategies. Given the more serious overestimate of $\mathrm{PM}_{2.5}$ in early periods (Fig. 2), the declining rates inferred from the CTL simulation might have been slightly overstated. With unchanged anthropogenic emissions, the increasing trend of haze pollution that would have occurred for Beijing highlights the unfavorable influences of recent changes in local meteorology. We explored if different thresholds of haze days would change the findings and found the variations are similar when a threshold of $75 \mu \mathrm{g} \mathrm{m}^{-3}$ is used (Fig. S2). Due to the overestimation of number of haze days by the model in early years, the declining rates of number of haze days inferred from the CTL simulation might have been overstated. As seen from Fig. S3, there is no notable declining trend in number of haze days inferred from observations over 2005-2016. However, it is consistent that both model and observations indicate rapid declines in number of haze days $(-4.8$ and $-3.0 \mathrm{~d}$ per winter, respectively) over 2012-2016. With fixed emissions, the MET simulation suggests that unfavorable climate conditions would have led to more haze days, emphasizing the significance of emission control in recent years. 

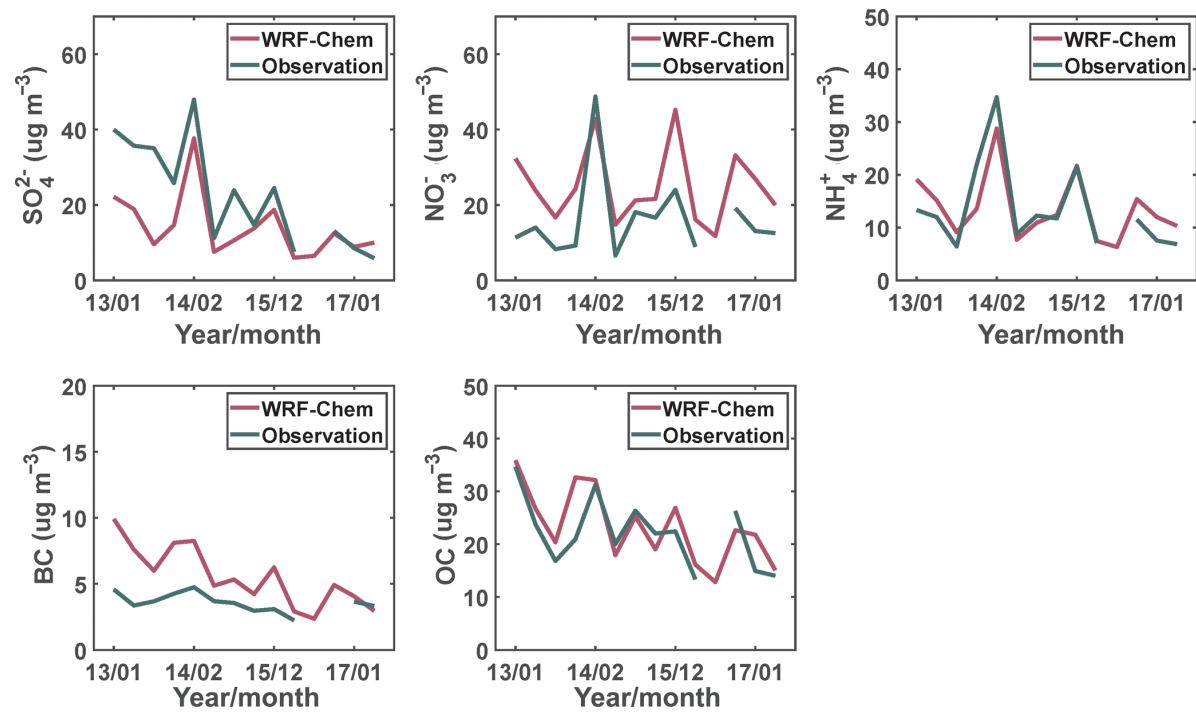

Figure 3. Simulated and observed temporal variations of monthly mean concentrations of $\mathrm{PM}_{2.5}$ chemical components from 2013 to 2017.

Using a similar approach, Cheng et al. (2019) found that meteorological conditions explain $12.1 \%$ of the improved $\mathrm{PM}_{2.5}$ air quality during 2013-2017, while large portions of the improvement are dominated by local $(65.4 \%)$ and regional $(22.5 \%)$ emission reductions. Zhou et al. (2019) concluded that emission reductions play a more important role than meteorological conditions in determining the declines in $\mathrm{PM}_{2.5}$ over 2011/2012-2017/2018. The current study examines longer-term trends since 2002, but the more favorable meteorological conditions mentioned in Cheng et al. (2019) are also illustrated in Fig. 4. Our findings also highlight the significance of emission reductions, especially after 2013, while the long-term trend of meteorological conditions since 2002 differs from it during 2013-2017.

\subsection{Significance of different meteorological variables}

To identify the key meteorological variables for the unfavorable influences on air quality, we applied a stepwise linear regression model (SLR) to determine the relative significance of multiple meteorological variables in terms of their contributions to the variations of $\mathrm{PM}_{2.5}$ concentrations. In an SLR model, the selected predictors are included in the regression equation one by one. The predictor that contributes the most to the model is included first, and the process is continued if the additional predictor can statistically improve the regression (Bendel and Afifi, 1977). Thus, SLR models are widely used to select meaningful predictors. In this study, boundary layer heights (BLH), precipitation (PREC), near-surface relative humidity (RH2), near-surface temperature (T2), and near-surface wind speeds (WS10) were selected as predictors for the SLR model. These variables were extracted from the WRF-Chem meteorological simulations with analyses nudging applied. Table 1 summarizes the $p$ values for each pre-
Table 1. The $p$ values for the stepwise linear regression model for Beijing.

\begin{tabular}{lr}
\hline Meteorological variables & $p$ values \\
\hline BLH & 0.38 \\
PREC & 0.64 \\
RH2 & 0.02 \\
T2 & 0.95 \\
WS10 & 0.00 \\
\hline
\end{tabular}

dictor. RH2 and WS10 were selected as the most significant predictors for wintertime $\mathrm{PM}_{2.5}$ in Beijing ( $p$ values $<0.05$ ). The influence of WS10 is greater than that of RH2. Shen et al. (2018) and Zhang et al. (2018) reported also that relative humidity $(\mathrm{RH})$ and meridional wind speeds drive stagnation and chemical production of $\mathrm{PM}_{2.5}$ in Beijing.

The impacts of RH on aerosol composition and processes in winter were examined using measurements in Beijing, and the largest impacts were found for the growth of sulfate and organic aerosols associated with coal combustion (Sun et al., 2013; Wang et al., 2017). Although RH2 has been shown to be a good predictor of $\mathrm{PM}_{2.5}$, it decreases slightly ( $-5.3 \%$ per decade) between the 2002 to 2016 period (Fig. 5a), which contradicts the predicted increasing trend of $\mathrm{PM}_{2.5}$ under fixed emissions (Fig. 4a). RH2 has been found to explain the interannual variability of $\mathrm{PM}_{2.5}$ but not the increasing trend. Thus, the variability of $\mathrm{RH} 2$ is unlikely to be the driver of enhanced $\mathrm{PM}_{2.5}$ under changing conditions of climate. As suggested by Ding et al. (2014), the decrease of RH2 was partly caused by the increase in surface temperature.

Between 2002 and 2016, simulated wintertime WS10 in Beijing declined gradually at a rate of $0.3 \mathrm{~m} \mathrm{~s}^{-1}$ per decade 

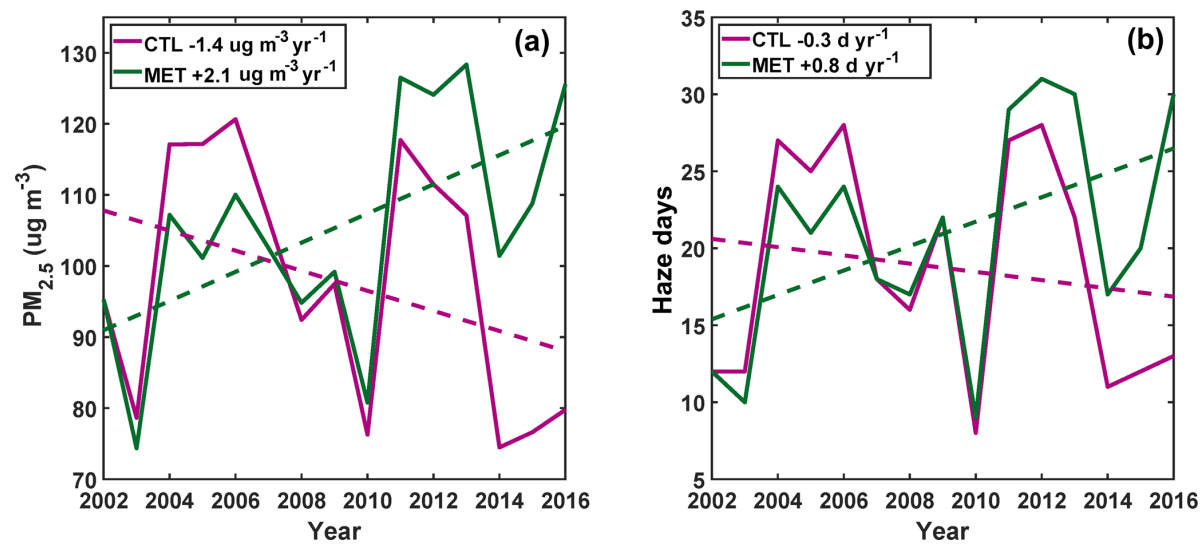

Figure 4. Wintertime mean concentrations of $\mathrm{PM}_{2.5}$ and number of haze days (defined as daily mean concentration above $150 \mu \mathrm{g} \mathrm{m}^{-3}$ ) from the CTL and MET simulations.
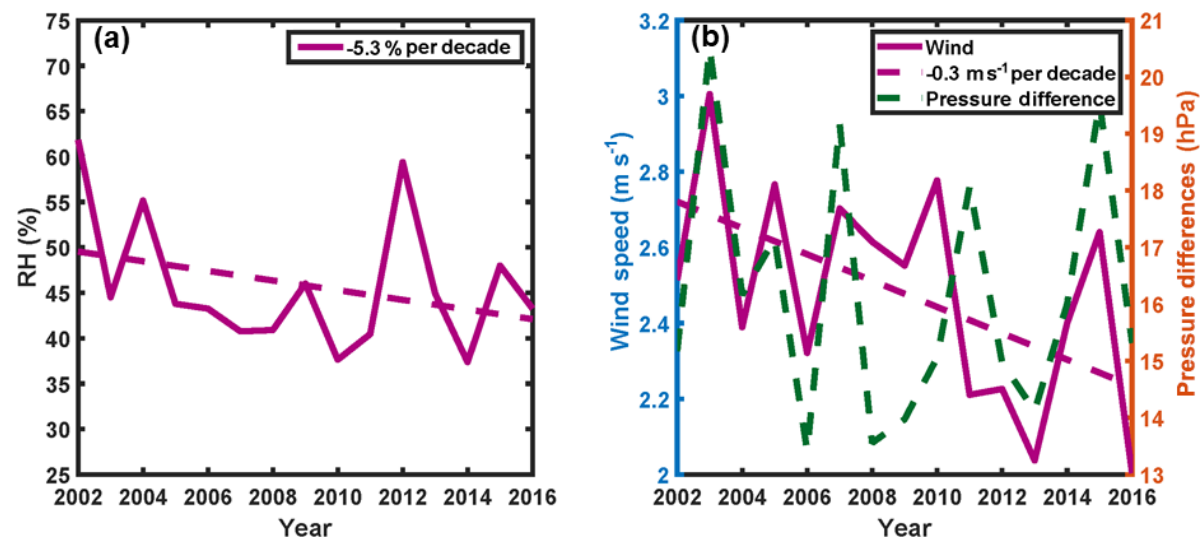

Figure 5. Simulated winter mean near-surface RH, wind speeds in Beijing with declining rates, and pressure difference indicating the intensity of East Asia winter monsoon.

(Fig. 5b), in agreement with the declining trends inferred from observations (Fig. S4). Weaker wintertime near-surface wind speeds are associated with enhanced $\mathrm{PM}_{2.5}$ concentrations and increasing numbers of haze days since 2002. In winter, the North China Plain features northwesterly winds associated with the East Asia winter monsoon (EAWM), properties of which depend largely on the development of both the Siberian High and the Aleutian Low (Jhun and Lee, 2004). We calculated the intensity of the EAWM index using the pressure difference between area mean sea level pressure (SLP; data were taken from MERRA-2 (The Modern-Era Retrospective analysis for Research and Applications, Version 2) reanalysis) over the region $40-50^{\circ} \mathrm{N}, 90-110^{\circ} \mathrm{E}$ and the area mean SLP over the region $40-60^{\circ} \mathrm{N}, 120-170^{\circ} \mathrm{E}$. These two regions represent the central focal areas of the Siberian High and the Aleutian Low, respectively. Figure 5b indicates that the variations of EAWM intensity have declined gradually over time, consistent with the variations of wind speeds in Beijing. The weakening of EAWM intensity is due partially to the increasing pressure in the regions of the Aleutian Low. As shown in Fig. 6, there is no signifi- cant change in SLP over the regions of the Siberian High, but SLP of the Aleutian Low intensity decreased significantly between 2002 and 2016 (more than $50 \mathrm{~Pa} \mathrm{yr}^{-1}$ ). Although no significant trend was observed for the strength of the Siberian High, the changes in the position of the Siberian High have been linked to wintertime air quality in China over the past decades (Jia et al., 2015).

Yin et al. (2015) found a significant negative correlation between winter haze and the East Asia winter monsoon from 1986 to 2010. Deterioration of air quality in China has been linked also to a weaker East Asia summer monsoon (Chin et al., 2012). The slacking of winds is observed not only for China (Sherman et al., 2017) but also for other countries including India (Gao et al., 2018b). Analyses using climate projections suggest that wind speeds in continental regions in the Northern Hemisphere will continue to decline under a warming climate (Karnauskas et al., 2018), imposing greater pressure on measures for future control of air pollution. 


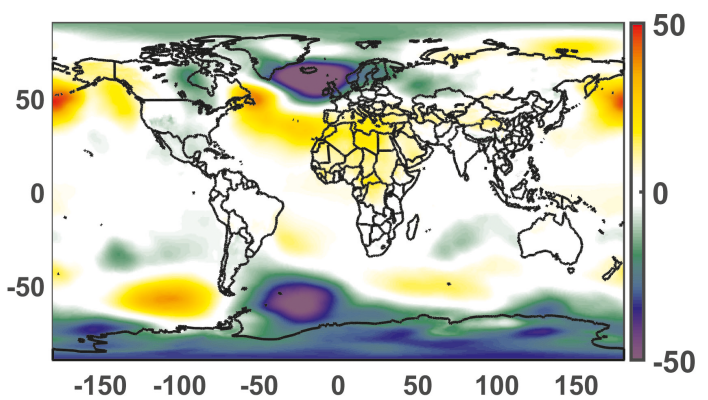

Figure 6. Trends of winter sea level pressure during the 2002-2016 period $\left(\mathrm{Pa} \mathrm{yr}^{-1}\right)$.

\section{Summary}

Combining field measurements and model simulations, we quantified the relative influences on $\mathrm{PM}_{2.5}$ concentrations in Beijing of anthropogenic emissions and meteorological conditions over the winters of 2002-2016. China's emission control strategies have been effective in reducing both mass concentrations of $\mathrm{PM}_{2.5}$ and the number of haze days. With fixed emissions, meteorological conditions over the study period should have resulted in an increase in haze in Beijing, but the strict emission control measures implemented by the government have suppressed the unfavorable influences associated with the recent climate. Using a statistical method, we concluded that RH2 and WS10 offer useful predictors for wintertime $\mathrm{PM}_{2.5}$ in Beijing, with the variations of WS10 in particularly good agreement with the increasing trend of $\mathrm{PM}_{2.5}$ concentrations with fixed emissions. The increasing trend of $\mathrm{PM}_{2.5}$ under unfavorable meteorological conditions was attributed further to the weakening of Aleutian Low and the EAWM. The variations of $\mathrm{PM}_{2.5}$ concentrations were investigated in this study for the urban Beijing region as were the changes in wind speeds. We do not exclude the possibility that the trend may have been influenced by other factors, including for example increases in surface roughness (Vautard et al, 2010).

Data availability. The measurements and model simulations data can be accessed through contacting the corresponding authors.

Supplement. The supplement related to this article is available online at: https://doi.org/10.5194/acp-20-1497-2020-supplement.

Author contributions. MG and MBM designed the study. MG performed model simulations and analyzed the data with help from SS, PS, JX, JKJ, and GRC. BZ and QZ provided the emission inventory. ZW, YW, ZL, DJ, JYX, and CL provided measurements. MG and MBM wrote the paper with inputs from all the other authors.
Competing interests. The authors declare that they have no conflict of interest.

Financial support. This work was supported by the special fund of the State Key Joint Laboratory of Environment Simulation and Pollution Control (grant no. 19K03ESPCT), the Harvard Global Institute, the Natural Science Foundation of Guangdong Province (no. 2019A1515011633), and the National Natural Science Foundation of China (no. NSFC91543202).

Review statement. This paper was edited by Xiaohong Liu and reviewed by Bin Zhu and three anonymous referees.

\section{References}

Bendel, R. B. and Afifi, A. A.: Comparison of stopping rules in forward "stepwise" regression, J. Am. Stat. Assoc., 72, 46-53, https://doi.org/10.1080/01621459.1977.10479905, 1977.

Chameides, W., Yu, H., Liu, S., Bergin, M., Xhou, X., Mearns, L., Wang, G., Kiang, C., Saylor, R. D., Luo, C., Huang, Y., Steiner, A., and Giorgi, F.: Study of the effects of atmospheric regional haze on agriculture?: enhance crop yields in China through emission controls?, P. Natl. Acad. Sci. USA, 96, 13626-13633, 1999.

Che, H., Zhang, X., Li, Y., Zhou, Z., Qu, J. J., and Hao, X.: Haze trends over the capital cities of 31 provinces in China, 1981-2005, Theor. Appl. Climatol., 97, 235-242, https://doi.org/10.1007/s00704-008-0059-8, 2009.

Chen, H. and Wang, H.: Haze days in North China and the associated atmospheric circulations based on daily visibility data from 1960 to 2012, J. Geophys. Res.-Atmos., 120, 5895-5909, https://doi.org/10.1002/2015JD023225, 2015.

Cheng, J., Su, J., Cui, T., Li, X., Dong, X., Sun, F., Yang, Y., Tong, D., Zheng, Y., Li, Y., Li, J., Zhang, Q., and He, K.: Dominant role of emission reduction in $\mathrm{PM}_{2.5}$ air quality improvement in Beijing during 2013-2017: a model-based decomposition analysis, Atmos. Chem. Phys., 19, 6125-6146, https://doi.org/10.5194/acp-19-6125-2019, 2019.

Cheng, Y., Zheng, G., Wei, C., Mu, Q., Zheng, B., Wang, Z., Gao, M., Zhang, Q., He, K., Carmichael, G., and Pöschl, U.: Reactive nitrogen chemistry in aerosol water as a source of sulfate during haze events in China, Sci. Adv., 2, e1601530, https://doi.org/10.1126/sciadv.1601530, 2016.

Chin, M.: Atmospheric science: Dirtier air from a weaker monsoon, Nat. Geosci., 5, 449-450, https://doi.org/10.1038/ngeo1513, 2012.

China State Council: Action Plan on Prevention and Control of Air Pollution, China State Council, Beijing, China, available at: http://www.gov.cn/zwgk/2013-09/12/content_2486773.htm (last access: 30 March 2019), 2013.

Ding, Y. H. and Liu, Y. J.: Analysis of long-term variations of fog and haze in China in recent 50 years and their relations with atmospheric humidity, Sci. China Earth Sci., 57, 36-46, https://doi.org/10.1007/s11430-013-4792-1, 2014.

Dockery, D. W., Pope, C. A., Xu, X., Spengler, J. D., Ware, J. H., Fay, M. E., Ferris Jr., B. G., and Speizer, F. E. : An association 
between air pollution and mortality in six U.S. cities, N. Engl. J. Med., 329, 1753-1759, 1993.

Gao, M., Carmichael, G. R., Wang, Y., Saide, P. E., Yu, M., Xin, J., Liu, Z., and Wang, Z.: Modeling study of the 2010 regional haze event in the North China Plain, Atmos. Chem. Phys., 16, 1673-1691, https://doi.org/10.5194/acp-16-1673-2016, 2016 a.

Gao, M., Carmichael, G. R., Saide, P. E., Lu, Z., Yu, M., Streets, D. G., and Wang, Z.: Response of winter fine particulate matter concentrations to emission and meteorology changes in North China, Atmos. Chem. Phys., 16, 11837-11851, https://doi.org/10.5194/acp-16-11837-2016, $2016 \mathrm{~b}$.

Gao, M., Liu, Z., Wang, Y., Lu, X., Ji, D., Wang, L., Li, M., Wang, Z., Zhang, Q., and Carmichael, G. R.: Distinguishing the roles of meteorology, emission control measures, regional transport, and co-benefits of reduced aerosol feedbacks in "APEC Blue", Atmos. Env., 167, 476-486, https://doi.org/10.1016/j.atmosenv.2017.08.054, 2017a.

Gao, M., Saide, P. E., Xin, J., Wang, Y., Liu, Z., Wang, Y., Wang, Z., Pagowski, M., Guttikunda, S. K., and Carmichael, G. R.: Estimates of Health Impacts and Radiative Forcing in Winter Haze in Eastern China through Constraints of Surface $\mathrm{PM}_{2.5}$ Predictions, Environ. Sci. Technol., 51, 2178-2185, https://doi.org/10.1021/acs.est.6b03745, $2017 \mathrm{~b}$.

Gao, M., Han, Z., Liu, Z., Li, M., Xin, J., Tao, Z., Li, J., Kang, J. E., Huang, K., Dong, X., Zhuang, B., Li, S., Ge, B., Wu, Q., Cheng, Y., Wang, Y., Lee, H. J., Kim, C. H., Fu, J. S., Wang, T., Chin, M., Woo, J. H., Zhang, Q., Wang, Z. and Carmichael, G. R.: Air quality and climate change, Topic 3 of the Model Inter-Comparison Study for Asia Phase III (MICS-Asia III) - Part 1: Overview and model evaluation, Atmos. Chem. Phys., 18(7), 4859-4884, https://doi.org/10.5194/acp-18-4859-2018, 2018a.

Gao, M., Ding, Y., Song, S., Lu, X., Chen, X., and McElroy, M. B.: Secular decrease of wind power potential in India associated with warming in the Indian Ocean, Sci. Adv., 4, eaat5256, https://doi.org/10.1126/sciadv.aat5256, 2018b.

Gao, Y., Liu, X., Zhao, C., and Zhang, M.: Emission controls versus meteorological conditions in determining aerosol concentrations in Beijing during the 2008 Olympic Games, Atmos. Chem. Phys., 11, 12437-12451, https://doi.org/10.5194/acp-11-124372011, 2011.

Guenther, A., Karl, T., Harley, P., Wiedinmyer, C., Palmer, P. I., and Geron, C.: Estimates of global terrestrial isoprene emissions using MEGAN (Model of Emissions of Gases and Aerosols from Nature), Atmos. Chem. Phys., 6, 3181-3210, https://doi.org/10.5194/acp-6-3181-2006, 2006.

He, H., Wang, Y., Ma, Q., Ma, J., Chu, B., Ji, D., Tang, G., Liu, C., Zhang, H., and Hao, J.: Mineral dust and NOx promote the conversion of $\mathrm{SO}_{2}$ to sulfate in heavy pollution days, Sci. Rep., 4, 1-6, https://doi.org/10.1038/srep04172, 2014.

Hung, H. M., Hsu, M. N., and Hoffmann, M. R.: Quantification of SO2Oxidation on Interfacial Surfaces of Acidic Micro-Droplets: Implication for Ambient Sulfate Formation, Environ. Sci. Technol., 52, 9079-9086, https://doi.org/10.1021/acs.est.8b01391, 2018.

Jhun, J. G. and Lee, E. J.: A new East Asian winter monsoon index and associated characteristics of the winter monsoon, J. Clim., 17, 711-726, https://doi.org/10.1175/15200442(2004)017<0711:ANEAWM>2.0.CO;2, 2004.
Jia, B., Wang, Y., Yao, Y., and Xie, Y.: A new indicator on the impact of large-scale circulation on wintertime particulate matter pollution over China, Atmos. Chem. Phys., 15, 11919-11929, https://doi.org/10.5194/acp-15-11919-2015, 2015.

Kang, H., Zhu, B., Gao, J., He, Y., Wang, H., Su, J., Pan, C., Zhu, T., and $\mathrm{Yu}, \mathrm{B}$.: Potential impacts of cold frontal passage on air quality over the Yangtze River Delta, China, Atmos. Chem. Phys., 19, 3673-3685, https://doi.org/10.5194/acp-19-3673-2019, 2019.

Karnauskas, K. B., Lundquist, J. K., and Zhang, L.: Southward shift of the global wind energy resource under high carbon dioxide emissions, Nat. Geosci., 11, 38-43, https://doi.org/10.1038/s41561-017-0029-9, 2018.

Li, L., Hoffmann, M. R., and Colussi, A. J.: Role of Nitrogen Dioxide in the Production of Sulfate during Chinese Haze-Aerosol Episodes, Environ. Sci. Technol., 52, 2686-2693, https://doi.org/10.1021/acs.est.7b05222, 2018.

Liu, T., Gong, S., He, J., Yu, M., Wang, Q., Li, H., Liu, W., Zhang, J., Li, L., Wang, X., Li, S., Lu, Y., Du, H., Wang, Y., Zhou, C., Liu, H., and Zhao, Q.: Attributions of meteorological and emission factors to the 2015 winter severe haze pollution episodes in China's Jing-Jin-Ji area, Atmos. Chem. Phys., 17, 2971-2980, https://doi.org/10.5194/acp-17-2971-2017, 2017.

Liu, Z., Hu, B., Wang, L., Wu, F., Gao, W., and Wang, Y.: Seasonal and diurnal variation in particulate matter $\left(\mathrm{PM}_{10}\right.$ and $\left.\mathrm{PM}_{25}\right)$ at an urban site of beijing: Analyses from a 9-year study, Environ. Sci. Pollut. Res., 22, 627-642, https://doi.org/10.1007/s11356014-3347-0, 2015.

Ministry of Environmental Protection of China and General Administration of Quality Supervision and Inspection Quarantine: Ambient air quality standard (GB 3095-2012), available at: http: //chinacsrmap.org/CSRTool_Show_EN.asp?ID=285 (last access: 28 January 2020), 2012.

Ramanathan, V. and Carmichael, G.: Global and regional climate changes due to black carbon, Nat. Geosci., 1, 221-227, 2008.

Randerson, J. T., Van Der Werf, G. R., Giglio, L., Collatz, G. J., and Kasibhatla, P. S.: Global Fire Emissions Database, Version 4.1 (GFEDv4), https://doi.org/10.3334/ORNLDAAC/1293, 2015.

Shen, L., Jacob, D. J., Mickley, L. J., Wang, Y., and Zhang, Q.: Insignificant effect of climate change on winter haze pollution in Beijing, Atmos. Chem. Phys., 18, 17489-17496, https://doi.org/10.5194/acp-18-17489-2018, 2018.

Sherman, P., Chen, X., and McElroy, M. B.: Wind-generated Electricity in China: Decreasing Potential, Inter-annual Variability and Association with Changing Climate, Sci. Rep., 7, 16294, https://doi.org/10.1038/s41598-017-16073-2, 2017.

Song, S., Gao, M., Xu, W., Shao, J., Shi, G., Wang, S., Wang, Y., Sun, Y., and McElroy, M. B.: Fine-particle $\mathrm{pH}$ for Beijing winter haze as inferred from different thermodynamic equilibrium models, Atmos. Chem. Phys., 18, 7423-7438, https://doi.org/10.5194/acp-18-7423-2018, 2018.

Song, S., Gao, M., Xu, W., Sun, Y., Worsnop, D. R., Jayne, J. T., Zhang, Y., Zhu, L., Li, M., Zhou, Z., Cheng, C., Lv, Y., Wang, Y., Peng, W., Xu, X., Lin, N., Wang, Y., Wang, S., Munger, J. W., Jacob, D. J., and McElroy, M. B.: Possible heterogeneous chemistry of hydroxymethanesulfonate (HMS) in northern China winter haze, Atmos. Chem. Phys., 19, 1357-1371, https://doi.org/10.5194/acp-19-1357-2019, 2019.

Sun, Y., Wang, Z., Fu, P., Jiang, Q., Yang, T., Li, J., and Ge, X.: The impact of relative humidity on aerosol composition and evolution 
processes during wintertime in Beijing, China, Atmos. Environ., 77, 927-934, https://doi.org/10.1016/j.atmosenv.2013.06.019, 2013.

Vautard, R., Cattiaux, J., Yiou, P., Thépaut, J. N., and Ciais, P.: Northern Hemisphere atmospheric stilling partly attributed to an increase in surface roughness, Nat. Geosci., 3, 756-761, https://doi.org/10.1038/ngeo979, 2010.

Wang, H.-J. and Chen, H.-P.: Understanding the recent trend of haze pollution in eastern China: roles of climate change, Atmos. Chem. Phys., 16, 4205-4211, https://doi.org/10.5194/acp16-4205-2016, 2016.

Wang, L., Ji, D., Li, Y., Gao, M., Tian, S., Wen, T., Liu, Z., Wang, L., Xu, P., Jiang, C., and Wang, Y.: The impact of relative humidity on the size distribution and chemical processes of major water-soluble inorganic ions in the megacity of Chongqing, China, Atmos. Res., 192, 19-29, https://doi.org/10.1016/j.atmosres.2017.03.016, 2017.

Wang, L. T., Wei, Z., Yang, J., Zhang, Y., Zhang, F. F., Su, J., Meng, C. C., and Zhang, Q.: The 2013 severe haze over southern Hebei, China: model evaluation, source apportionment, and policy implications, Atmos. Chem. Phys., 14, 3151-3173, https://doi.org/10.5194/acp-14-3151-2014, 2014.

Wang, X., Zhang, R., and Yu, W.: The Effects of $\mathrm{PM}_{2.5}$ Concentrations and Relative Humidity on Atmospheric Visibility in Beijing, J. Geophys. Res.-Atmos., 2235-2259, https://doi.org/10.1029/2018JD029269, 2019.

Wang, Y., Zhang, Y., Schauer, J. J., de Foy, B., Guo, B., and Zhang, Y.: Relative impact of emissions controls and meteorology on air pollution mitigation associated with the Asia-Pacific Economic Cooperation (APEC) conference in Beijing, China, Sci. Total Env., 571, 1467-1476, https://doi.org/10.1016/j.scitotenv.2016.06.215, 2016.

Wild, O., Zhu, X., and Prather, M. J.: Fast-J: Accurate simulation of in- and below-cloud photolysis in tropospheric chemical models, J. Atmos. Chem., 37, 245-282, https://doi.org/10.1029/2006JD008007, 2000.

Wu, D., Tie, X., Li, C., Ying, Z., Lau, A. K. H., Huang, J., Deng, X., and Bi, X.: An extremely low visibility event over the Guangzhou region: A case study, Atmos. Environ., 39, 65686577, https://doi.org/10.1016/j.atmosenv.2005.07.061, 2005.
Xing, J., Zhang, Y., Wang, S., Liu, X., Cheng, S., Zhang, Q., Chen, Y., Streets, D. G., Jang, C., Hao, J., and Wang, W.: Modeling study on the air quality impacts from emission reductions and atypical meteorological conditions during the 2008 Beijing Olympics, Atmos. Env., 45, 1786-1798, https://doi.org/10.1016/j.atmosenv.2011.01.025, 2011.

Yang, Y., Liao, H., and Lou, S.: Increase in winter haze over eastern China in recent decades: Roles of variations in meteorological parameters and anthropogenic emissions, J. Geophys. Res., 121, 13050-13065, https://doi.org/10.1002/2016JD025136, 2016.

Yin, Z., Wang, H., and Yuan, D.: Interdecadal increase of haze in winter over North China and the Huang-huai Area and the weakening of the East Asia Winter Monsoon, Chinese Sci. Bull., 60, 1395-1400, https://doi.org/10.1360/n972014-01348, 2015.

Zaveri, R. A., Easter, R. C., Fast, J. D., and Peters, L. K.: Model for Simulating Aerosol Interactions and Chemistry (MOSAIC), J. Geophys. Res., 113, D13204, https://doi.org/10.1029/2007JD008782, 2008.

Zaveri, R. A. and Peters, L. K.: A new lumped structure photochemical mechanism for large-scale applications, J. Geophys. Res., 104, 30387, https://doi.org/10.1029/1999JD900876, 1999.

Zhang, Z., Kim, S. J., and Ma, Z.: Significant decrease of $\mathrm{PM}_{2.5}$ in Beijing based on long-term records and KolmogorovZurbenko filter approach, Aero. Air Qual. Res., 18, 711-718, https://doi.org/10.4209/aaqr.2017.01.0011, 2018

Zheng, B., Tong, D., Li, M., Liu, F., Hong, C., Geng, G., Li, H., Li, X., Peng, L., Qi, J., Yan, L., Zhang, Y., Zhao, H., Zheng, Y., He, K., and Zhang, Q.: Trends in China's anthropogenic emissions since 2010 as the consequence of clean air actions, Atmos. Chem. Phys., 18, 14095-14111, https://doi.org/10.5194/acp-18-140952018, 2018.

Zhou, W., Gao, M., He, Y., Wang, Q., Xie, C., Xu, W., Zhao, J., Du, W., Qiu, Y., Lei, L., Fu, P., Wang, Z., Worsnop, D. R., Zhang, Q., and Sun, Y.: Response of aerosol chemistry to clean air action in Beijing, China: Insights from two-year ACSM measurements and model simulations, Environ. Polutt., 255, 113345, https://doi.org/10.1016/j.envpol.2019.113345, 2019. 